\title{
PENGARUH PROMOSI DAN INOVASI PRODUK TERHADAP KEPUTUSAN PEMBELIAN HONDA MOBILIO (Survei Pada Pengguna Honda Mobilio di Karawang)
}

\author{
Mulyani Soleha ${ }^{1)}$, Nanda Eka Pawitri S ${ }^{2}$ \\ Email : ${ }^{1}$ ) mulyani.soleha17155@ student.unsika.ac.id, ${ }^{2}$ ) nanda.eka17159@student.unsika.ac.id \\ ${ }^{1,2}$ ) Program Studi Manajemen, Universitas Singaperbangsa Karawang
}

\begin{abstract}
Abstrak
Penelitian ini bertujuan untuk mengetahui pengaruh promosi dan inovasi produk terhadap keputusan pembelian Honda Mobilio. Variabel dependen pada penelitian ini adalah Keputusan Pembelian (Y), dan variabel independen adalah Promosi (X1) dan Inovasi Produk (X2). Metode penelitian ini menggunakan metode kuantitatif dengan teknik pengambilan sampel non probability sampling, yaitu dengan teknik purposive sampling terhadap 100 orang yang membeli produk Honda Mobilio melalui penyebaran kuesioner (angket)._Uji instrument dilakukan pada penelitian ini adalah dengan uji validitas dan uji reabilitas. Metode analisis data dilakukan menggunakan uji statistic data deskriptif dan verifikatif. Data verifikatif menggunakan uji asumsi klasik, pengujian hipotesis, dan koefisien determinasi $\left(R^{2}\right)$ dengan menggunakan program Software SPSS versi 16.0 dan Lisrel versi 8.8. Hasil penelitian menunjukkan adanya pengaruh promosi dan inovasi produk secara simultan terhadap keputusan pembelian Honda Mobilio. Berdasarkan hasil uji parsial dapat dilihat bahwa promosi dan inovasi produk berpengaruh secara positif dan signifikan terhadap keputusan pembelian Honda Mobilio.
\end{abstract}

Kata kunci: Promosi, Inovasi Produk, Keputusan Pembelian.

\begin{abstract}
This study aimed to determine the effect of product promotion and innovation on Honda Mobilio purchasing decisions. The dependent variable in this study was the Purchasing Decision (Y), and the independent variables are Promotion (X1) and Product Innovation (X2). The population in this study were Honda Mobilio users in Karawang. The sample was determined by purposive sampling technique, with 100 respondents. Data collection techniques in this study were primary data that is obtained through questionnaires (questionnaire). The analysis technique used in this study is the instrument test (validity and reliability test), the classic assumption test, hypothesis testing, and the coefficient of determination using the SPSS software program version 16.0 and the Lisrel Program. The results showed a simultaneous influence of product promotions and innovations on Honda Mobilio's purchasing decisions. Based on the partial test results, it can be seen that product promotion and change have a positive and significant effect on the purchase decision of Honda Mobilio.
\end{abstract}

Keywords: Promotion, Product Innovation, Purchasing Decisions.

\section{PENDAHULUAN}

Perkembangan zaman di era globalisasi saat ini persaingan di dunia otomotif semakin pesat, sehingga persaingan diantara produsen otomotif dunia terjadi sedemikian ketat dalam menciptakan produk, hal ini dapat terlihat dengan bermunculnya inovasi-inovasi baru untuk dapat memenuhi selera pasar serta mampu mempengaruhi keputusan konsumen dalam melakukan pembelian. Salah satu industri yang mengalami persaingan sangat ketat adalah industri otomotif, khususnya persaingan pada industri mobil. Kebutuhan sarana transportasi merupakan kebutuhan masyarakat yang terus berkembang sejalan dengan semakin tingginya mobilitas masyarakat dan meningkatnya taraf kehidupan ekonomi masyarakat. Hal ini mengakibatkan terjadinya persaingan diantara perusahaan mobil untuk dapat menarik konsumen agar menggunakan produknya.

Produksi otomotif dunia yang terus berkembang dalam memenuhi kebutuhan konsumen, Indonesia termasuk salah satu pasar otomotif paling potensial di dunia. Perkembangan pesat industri otomotif di Indonesia membuat tingkat persaingannya menjadi ketat. Para produsen mobil terus melakukan inovasi terhadap 
produknya. Hal ini terlihat dari semakin beraneka ragamnya merek dan jenis mobil di Indonesia. Hampir semua industri di Indonesia ada campur tangan pemain asing walaupun mereka tidak terlibat secara langsung di dalam industri tersebut, salah satu industry yang banyak merek asing adalah industri otomotif yaitu mobil $M P V$. Multi Purpose Vehicle (MPV) adalah salah satu jenis kendaraan keluarga yang lebih besar dan lebih tinggi dari jenis sedan dan hatchback, karena mobil ini memiliki kapasitas penumpang yang lebih dari 5 orang, sehingga mampu memuat seluruh anggota keluarganya, yang biasanya terdiri dari 5 orang. Prioritas dari jenis mobil $M V P$ ini adalah interior mobil yang besar dan nyaman, karena mobil ini khususkan untuk kenyaman seluruh keluarga terutama dalam perjalanan jauh, apalagi modelnya yang stylist dan diimbangi dengan warnawarni yang menarik serta interior memikat.

\section{Tabel 1. Data Penjualan Mobil MVP dan $S U V$} Tahun 2014

\begin{tabular}{|c|c|c|c|}
\hline & $\begin{array}{c}\text { Agustus } \\
\mathbf{2 0 1 4}\end{array}$ & $\begin{array}{c}\text { Juli } \\
\mathbf{2 0 1 4}\end{array}$ & $\begin{array}{c}\text { Change \% } \\
\text { better } \\
\text { (worse) }\end{array}$ \\
\hline MVP (unit) & 16.525 & 15.829 & $4,4 \%$ \\
\hline SUV (unit) & 3.758 & 3.684 & $2,0 \%$ \\
\hline
\end{tabular}

Sumber : Online The Gren Blok dalam Erdiana (2015)

Menurut data penjualan mobil $M P V$ sendiri adalah varian mobil terlaris di Indonesia, karena selain nyaman, irit, juga serbaguna. Serbaguna disini dalam artian mobil bisa digunakan untuk kendaraan harian, karena praktis dan tidak terlalu besar, bisa digunakan untuk bepergian bersama keluarga karena kapasitas penumpang yang cukup besar, bisa juga digunakan sebagai kendaraan usaha/niaga, karena mempunyai kabin yang luas sehingga bisa mengangkut banyak barang.Penjualan mobil serba guna atau Multi Purpose Vehicle (MPV) masih menjadi paling favorit di Indonesia. Gabungan Industri Kendaraan bermotor Indonesia (Gaikindo) mencatat, kelas $M P V$ selalu menyumbangkan penjualan terbanyak. Produk yang ditawarkan Honda yaitu Honda Mobilio merupakan type mobil Multi Purpose Vehicle (MPV). Honda mobilio hadir di Indonesia bertepatan dengan mulai aktifnya pabrik kedua Honda Prospect Motor (HPM) yang akan khusus untuk memproduksi mobil Honda Mobilio ini. Varian Mobilio mencantumkan harga yang sangat terjangkau dengan segi kualitas produk yang ditawarkan memiliki fitur canggih dan nomer satu adalah safety.

Honda Mobilio pertama kali diperkenalkan oleh PT Honda Prospect Motor (HPM) pada bulan September 2013. Top Brand Index dan Penjualan low MPV Honda Mobilio ini dalam beberapa tahun terakhir terus menurun, babak belur di tengah sengitnya persaingan.

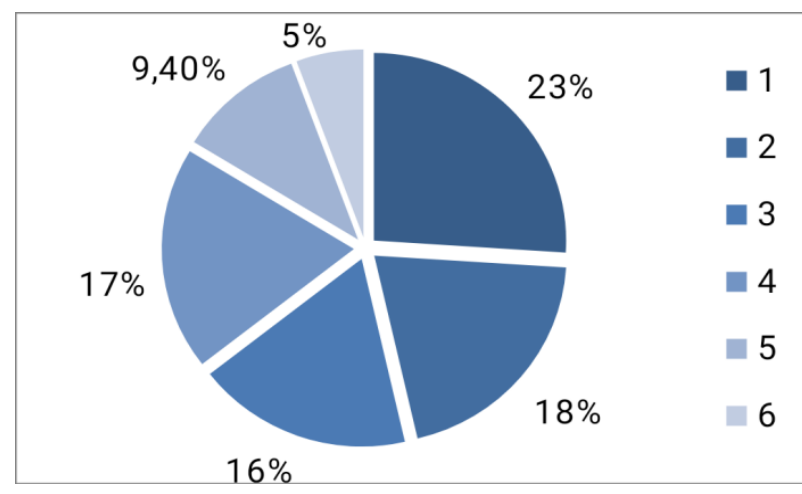

Gambar 1. Top Brand Index Honda Mobilio

Tahun 2014 - 2019

Sumber : www.motoris.id

Berdasarkan gambar Top Brand Index diatas, Top Brand Index Honda Mobilio mengalami penurunan dari tahun ke tahun.

Tabel 2. Volume Penjualan Honda Mobilio Tahun $2014-2018$

\begin{tabular}{|c|c|}
\hline Tahun & Volume Penjualan/Unit \\
\hline 2014 & 79.288 \\
\hline 2015 & 42.932 \\
\hline 2016 & 39.482 \\
\hline 2017 & 35.430 \\
\hline 2018 & 24.373 \\
\hline
\end{tabular}

Sumber : www.motoris.id

Saat diluncurkan penjualan Honda Mobilio langsung meningkat dengan volume penjualan 79.288 unit, dan di tahun berikutnya tiba-tiba menukik tajam, sehingga menjadi 42.932 unit dan bahkan di dua tahun terahir yakni 2016 dan 2017 'musim gugur' Mobilio masih berlanjut. Penjualan yang dibukukan hanya sebanyak 39.482 unit dan 35.430 unit, pada tahun 2018 penjualan Honda Mobilio hanya sebanyak 24.372 unit. Pada dasarnya kebutuhan dan keinginan konsumen selalu mengalami perubahan bahkan cenderung meningkat dari waktu ke waktu maka perusahaan perlu mengadakan suatu riset pemasaran dalam usahanya untuk mengetahui produk apa yang sebenarnya dibutuhkan dan diinginkan oleh konsumen. Keputusan pembelian dipengaruhi oleh faktor stimulus atau rangsangan pemasaran seperti promosi produk yang menarik, dan inovasi produk yang dilakukan. Promosi merupakan faktor penting dalam mewujudkan tujuan penjualan suatu perusahaan, dengan promosi perusahaan dapat mengkomunikasikan produk kepada konsumen.

Bagi Honda Mobilio promosi merupakan bagian yang sangat penting dan menjadi salah satu kunci sukses keberhasilan Honda Mobilio dalam meraih pasar. Konsep promosi yang dikembangkan Honda Mobilio adalah konsep yang efisien akan dianggap cukup efektif, yaitu dengan cara promosi secara langsung kepada pelanggan, dan menggunakan media online yaitu Facebook dan Instagram. Faktor lain yang mempengaruhi keputusan 
membeli adalah inovasi produk, dimana perusahaan yang menerapkan struktur dan strategi yang memusatkan pemilihan waktu pengembangan teknologi dan persaingan. Inovasi akan meningkatkan nilai tambah dari suatu produk, menciptakan suatu produk baru yang dapat memberikan solusi yang lebih baik bagi pemecahan masalah yang dihadapi konsumen dan inovasi harus mampu membuat produk berbeda di mata konsumen sehingga konsumen lebih tertarik membeli produk tersebut dibandingkan produk pesaing. Bagi Honda Mobilio Inovasi produk merupakan bagian penting dalam keberhasilan dalam meraih pasar. Inovasi produk yang dikembangkan Honda Mobilio adalah menciptakan inovasi produk yang beragam, sesuai dan berkualitas.

Penelitian ini dilakukan di kota Karawang, karena kota Karawang merupakan salah satu kota dengan laju pertumbuhan penduduk semakin meningkat. Kondisi ini menguatkan bahwa tingkat pertumbuhan penduduk mengindikasikan daya beli yang tinggi dan pola konsumsi masyarakat yang menjadikan produk otomotif terutama mobil Honda Mobilio menjadi sebuah pertimbangan konsumen dalam membeli mobil yang irit demi mendukung aktivitas sehari-hari. Berdasarkan uraian tersebut, maka judul penelitian ini adalah "Pengaruh Promosi Dan Inovasi Produk Terhadap Keputusan Pembelian Honda Mobilio (Survei Pada Pengguna Honda Mobilio Di Kota Karawang)".

Berdasarkan latar belakang masalah tersebut, maka rumusan masalah dari penelitian ini yaitu Bagaimana gambaran promosi pada Honda Mobilio di Karawang? Bagaimana gambaran inovasi produk pada Honda Mobilio di Karawang? Bagaimana gambaran keputusan pembelian pada Honda Mobilio di Karawang? Seberapa besar pengaruh promosi terhadap keputusan pembelian pada Honda Mobilio di Karawang? Seberapa besar pengaruh inovasi produk terhadap keputusan pembelian Honda Mobilio di Karawang? Seberapa besar pengaruh promosi dan inovasi produk terhadap keputusan pembelian pada Honda Mobilio di Karawang?

Adapun tujuan dari penelitian ini adalah sebagai berikut: Untuk mengetahui gambaran promosi pada Honda Mobilio di Karawang. Untuk mengetahui gambaran inovasi produk pada Honda Mobilio di Karawang. Untuk mengetahui gambaran keputusan pembelian pada Honda Mobilio di Karawang. Untuk mengetahui besar pengaruh promosi terhadap keputusan pembelian pada Honda Mobilio di Karawang. Untuk mengetahui besar pengaruh inovasi produk terhadap keputusan pembelian Honda Mobilio di Karawang. Untuk mengetahui besar pengaruh promosi dan inovasi produk terhadap keputusan pembelian pada Honda Mobilio di Karawang.

\section{METODE PENELITIAN}

Jenis data yang digunakan yaitu data primer. Dimana peneliti menggunakan kuesioner (angket) untuk mengumpulkan informasi. Populasi dalam penelitian ini adalah populasi tak terhingga, maka populasi yang terpilih yaitu pengguna Honda Mobilio di Karawang. Menurut Sugiyono (2017) menyatakan bahwa sampel adalah bagian dari jumlah dan karakteristik yang dimiliki oleh populasi tersebut. Karena jumlahnya tidak diketahui secara pasti, maka digunakan teknik penentuan jumlah sampel untuk populasi tidak terhingga sebagai berikut Penentuan jumlah sampel ini yang akan dipilih menggunakan tingkat keyakinan $95 \%$ atau 1,96 dan tingkat kesalahan sebesar $10 \%$ karena setiap penelitian tidak mungkin hasilnya sempurna $100 \%$, makin besar tingkat kesalahan maka semakin sedikit ukuran sampel dan perhitungan sebagai berikut:

Rumus:

$$
\begin{aligned}
& \mathrm{n}=1,962^{2} / 4(0,1)^{2} \\
& \mathrm{n}=3,842 / 0,04 \\
& \mathrm{n}=96,04 \\
& \mathrm{n}=97
\end{aligned}
$$

Berdasarkan perhitungan menggunakan rumus diatas diperoleh sampel yang ideal minimal sebesar 96,04 yang dibulatkan menjadi 97 sampel. Namun nantinya jumlah sampel yang digunakan dalam penelitian ini adalah sejumlah 100 responden.

\section{Hasil Uji Validitas dan Reliabilitas}

Uji instrument dilakukan pada penelitian ini adalah dengan uji validitas dan reliabilitas. Metode analisis data dilakukan menggunakan uji asumsi klasik, pengujian hipotesis, dan koefisien determinasi $\left(R^{2}\right)$ dengan menggunakan program Software SPSS versi 16.0 dan Lisrel versi 8.8.

\section{Hasil Uji Validitas}

Penelitian ini menguji validitas dari instrumen promosi sebagai variabel $\mathrm{X} 1$ dengan jumlah pernyataan 9, inovasi produk sebagai variabel X2 dengan jumlah pernyataan 9, dan keputusan pembelian sebagai variabel Y dengan jumlah pernyataan 9. Berikut hasil uji validitas instrument kuesioner penelitian:

Tabel 3. Hasil Uji Validitas

\begin{tabular}{|c|c|c|c|}
\hline Variabel & $\begin{array}{c}\text { No } \\
\text { Item }\end{array}$ & $\begin{array}{c}\text { Sig(2- } \\
\text { tailed) }\end{array}$ & Keterangan \\
\hline \multirow{4}{*}{ Promosi } & 1 & 0,704 & Valid \\
\cline { 2 - 4 } & 2 & 0,778 & Valid \\
\cline { 2 - 4 } & 3 & 0,743 & Valid \\
\cline { 2 - 4 } & 4 & 0,767 & Valid \\
\cline { 2 - 4 } & 5 & 0,853 & Valid \\
\cline { 2 - 4 } & 6 & 0,761 & Valid \\
\cline { 2 - 4 } & 7 & 0,727 & Valid \\
\cline { 2 - 4 } & 8 & 0,725 & Valid \\
\cline { 2 - 4 } & 9 & 0,793 & Valid \\
\hline \multirow{4}{*}{ Inovasi } & 10 & 0,754 & Valid \\
\cline { 2 - 4 } & 11 & 0,761 & Valid \\
\cline { 2 - 4 } & 12 & 0,817 & Valid \\
\cline { 2 - 4 } & 13 & 0,755 & Valid \\
\cline { 2 - 4 } & 14 & 0,722 & Valid \\
\hline
\end{tabular}




\begin{tabular}{|c|c|c|c|}
\hline \multirow{5}{*}{} & 15 & 0,744 & Valid \\
\cline { 2 - 4 } & 16 & 0,805 & Valid \\
\cline { 2 - 4 } & 17 & 0,836 & Valid \\
\cline { 2 - 4 } Keputusan & 18 & 0,81 & Valid \\
\hline \multirow{5}{*}{ pembelian } & 19 & 0,861 & Valid \\
\cline { 2 - 4 } & 20 & 0,831 & Valid \\
\cline { 2 - 4 } & 21 & 0,798 & Valid \\
\cline { 2 - 4 } & 22 & 0,788 & Valid \\
\cline { 2 - 4 } & 23 & 0,826 & Valid \\
\cline { 2 - 4 } & 24 & 0,841 & Valid \\
\cline { 2 - 4 } & 25 & 0,814 & Valid \\
\cline { 2 - 4 } & 26 & 0,842 & Valid \\
\cline { 2 - 4 } & 27 & 0,85 & Valid \\
\hline
\end{tabular}

Sumber: Data Primer diolah, 2019

Berdasarkan pada tabel 3 diatas menunjukkan bahwa sembilan indikator per variabel yang digunakan didalam penelitian ini di kategorikan valid.

\section{Hasil Uji Reliablitas}

Uma Sekaran dan Roger Bougie (2017:35) menyataan bahwa reliabilitas adalah uji bagaimana instrumen pengukuran secara konsisten mengukur apapun yang sedang diukur, maka dapat disimpulkan bahwa reliabilitas adalah suatu uji untuk mengukur bagaimana konsistensi terkait. Perhitungan reliabilitas dalam pada penelitian ini menggunakan rumus Cronbach Alpha. Rumus Alpha digunakan untuk mencari reliabilitas instrumen yang skornya bukan 1 dan 0 , misalnya angket atau soal bentuk uraian. Berikut hasil uji reliabilitas instrument kuesioner penelitian :

Tabel 4. Hasil Reliabilitas

\begin{tabular}{|c|c|c|}
\hline Variabel & $\begin{array}{c}\text { Cronbach's } \\
\text { Alpha }\end{array}$ & Keterangan \\
\hline Promosi & 0,909 & Reliabel \\
\hline Inovasi produk & 0,942 & Reliabel \\
\hline Keputusan pembelian & 0,918 & Reliabel \\
\hline
\end{tabular}

Sumber: Data Primer diolah, 2019

Berdasarkan pada tabel 4, ketiga variabel yang digunakan didalam penelitian ini terkategori reliabel karena memiliki nilai Cronbach's Alpha > 0,60 yang berarti bahwa alat ukur dalam penelitian ini merupakan alat ukur yang konsisten dan dapat dipercaya.

\section{HASIL DAN PEMBAHASAN}

Karakteristik Responden Berdasarkan Jenis Kelamin

Pengumpulan data melalui kuesioner mengenai karakteristik responden berdasarkan jenis kelamin disajikan pada tabel 5 sebagai berikut:

\section{Tabel 5. Profil Responden Berdasarkan Jenis Kelamin}

\begin{tabular}{|c|c|c|}
\hline Jenis Kelamin & Frequency & Percent \\
\hline Perempuan & 30 & 28.8 \\
\hline Laki-Laki & 74 & 71.2 \\
\hline
\end{tabular}

\begin{tabular}{|c|c|c|}
\hline Total & 104 & 100.0 \\
\hline
\end{tabular}

Sumber: Data Primer diolah, 2019

Berdasarkan Tabel 5 menunjukkan bahwa sebagian besar responden yang diteliti pada pengguna Honda Mobilio di Karawang adalah jenis kelamin laki-laki dengan valid precent $71,2 \%$.

\section{Karakteristik Responden Berdasarkan Profesi}

Pengumpulan data melalui kuesioner mengenai karakteristik responden berdasarkan profesi disajikan pada tabel 6 sebagai berikut :

Tabel 6. Profil Responden Berdasarkan Profesi

\begin{tabular}{|l|r|r|}
\hline \multicolumn{1}{|c|}{ Profesi } & \multicolumn{1}{c|}{ Frequency } & \multicolumn{1}{c|}{ Percent } \\
\hline pelajar/mahasiswa & 33 & 0,33 \\
\hline Wiraswasta & 14 & 0,14 \\
\hline Pegawai Swasta & 32 & 0,32 \\
\hline PNS & 5 & 0,05 \\
\hline Lain-Lain & 16 & 0,16 \\
\hline Total & 100 & 100 \\
\hline
\end{tabular}

Sumber : Data Primer, diolah, 2019

Berdasarkan tabel 6 menunjukkan bahwa profesi responden hampir setengahnya oleh pelajar/mahasiswa yakni 33 orang atau $33 \%$ dan pegawai swasta yakni 32 orang atau $32 \%$. Hal ini dikarenakan sebagian besar responden adalah kalangan pelajar/mahasiswa dan pegawai swasta.

Tabel 7. Profil Responden Berdasarkan Pendapatan Perbulan

\begin{tabular}{|l|r|r|}
\hline & Frequency & Percent \\
\hline$<\operatorname{Rp~} 500.000$ & 41 & 0,41 \\
\hline$>\operatorname{Rp~} 8.000 .000$ & 6 & 0,06 \\
\hline $\operatorname{Rp~} 500.000-\operatorname{Rp~} 2.000 .000$ & 6 & 0,06 \\
\hline $\operatorname{Rp~} 4.000 .000-\operatorname{Rp~} 8.000 .000$ & 27 & 0,27 \\
\hline $\operatorname{Rp} 2.000 .000-\operatorname{Rp~} 4.000 .000$ & 20 & 0,2 \\
\hline Total & 100 & 100 \\
\hline
\end{tabular}

Sumber : Data Primer, diolah, 2019

Berdasarkan tabel 7 menunjukkan bahwa penghasilan responden hampir setengahnya kurang dari < Rp 500.000 yakni 41 orang atau $41 \%$. Hal ini dikarenakan sebagian besar responden adalah kalangan pelajar/mahasiswa, sehingga dapat dipastikan dengan nyata penghasilan mereka tidak tetap atau kurang dari Rp. 500.000. Dan penghasilan Rp 4.000.000 - Rp 8.000.000 sebesar 27 orang atau $27 \%$ yang didominasi oleh kalangan pegawai swasta.

\section{Uji Hipotesis}

\section{Analisis Koefisien Determinasi}

LISREL Estimates (Maximum Likelihood)

Structural Equations

$\mathrm{Y}=0.47 * \mathrm{X} 2+0.36 * \mathrm{X} 1$, Errorvar $=11.02, \mathrm{R}^{2}=0.65$ 

(0.10)
$(0.11)$
$(1.57)$
4.62
3.38
7.00

Nilai R2 (koefisien determinasi) sebesar 65\%. Artinya $65 \%$ keputusan pembelian (Y) mampu dijelaskan oleh promosi (X1) dan inovasi produk (X2), sisanya 35\% dijelaskan oleh variabel lain.

2. Uji Hipotesis Secara Simultan

LISREL Estimates (Maximum Likelihood)

Structural Equations

$\mathrm{Y}=0.47 * \mathrm{X} 2+0.36 * \mathrm{X} 1$, Errorvar $=11.02, \mathrm{R}^{2}=0.65$
(0.10) (0.11)
4.62
3.38
7.00

Nilai R2 (koefisien determinasi) sebesar 65\%. Artinya $65 \%$ keputusan pembelian (Y) mampu dijelaskan oleh promosi (X1) dan inovasi produk (X2), sisanya 35\% dijelaskan oleh variabel lain.

\section{Uji Hipotesis Secara Parsial}

$\begin{array}{ccc}\text { Standardized Solution } \\ \text { BETA } \\ \text { X2 } & \text { Y } \\ & ----- & ------- \\ \text { X2 } & -- & -- \\ \text { Y } & 0.49 & --\end{array}$

Koefisien Jalur (Standardized Solution)

Beta (Pengaruh antar endogen)

$\mathrm{P} 32=0.49$ adalah koefisien jalur endogen $\mathrm{X} 2$ terhadap endogen $\mathrm{Y}$

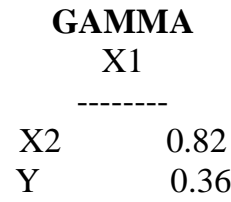

Gamma (pengaruh antara variabel eksogen dan endogen)

$\mathrm{P} 21=0.82$ adalah jalur eksogen $\mathrm{X} 1$ terhadap endogen $\mathrm{X} 2$

$\mathrm{PY} 1=0.36$ adalah koefisien jalur eksogen $\mathrm{X} 1$ terhadap endogen $\mathrm{Y}$

\begin{tabular}{lc}
\multicolumn{2}{c}{ Standardized Total Effects of $\mathbf{X}$ on $\mathbf{Y}$} \\
\multicolumn{1}{c}{$\mathrm{X} 1$} \\
$\mathrm{X} 2$ & ------ \\
$\mathrm{Y}$ & 0.82 \\
& 0.76
\end{tabular}

Pengaruh total eksogen dan endogen:

Pengaruh total X1 terhadap X2 $=0.82$

Pengaruh total $\mathrm{X} 1$ terhadap $\mathrm{Y}=0.76$

Pengaruh total X1 terhadap $\mathrm{Y}=\mathrm{PY} 1+\mathrm{P} 21 \mathrm{P} 32=0.36+$ $(0.82)(0.49)=0.76$

\section{Standardized Indirect Effects of $\mathrm{X}$ on $\mathrm{Y}$}

$\begin{array}{ll} & \mathrm{X} 1 \\ \mathrm{X} 2 & ----\end{array}$

$$
\mathrm{Y} \quad 0.40
$$

Pengaruh tidak langsung eksogen dan endogen:

Pengaruh tidak langsng $\mathrm{X} 1$ terhadap $\mathrm{Y}=\mathrm{P} 21 \mathrm{P} 32=$ $(0.82)(0.49)=0,40$

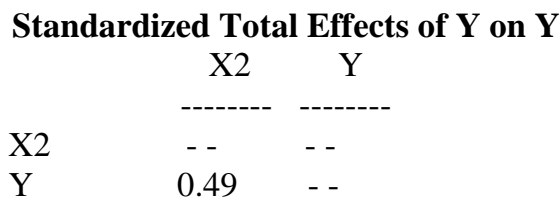

Pengaruh total endogen dan endogen:

Pengaruh total X2 terhadap $\mathrm{Y}=\mathrm{P} 32=(0.49)$

Pengaruh total endogen dan endogen:

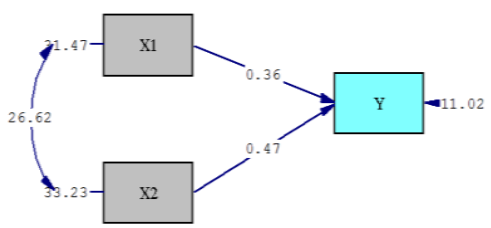

Chi-Square $=0.00, d f=0, P-v a l u e=1.00000$, RMSEA $=0.000$

\section{Gambar 2. Diagram Jalur}

Dari diagram jalur diatas menunjukkan bahwa tidak terdapat jalur berwarna merah, hal tersebut menunjukkan semua koefisien jalur signifikan.

\section{PEMBAHASAN HASIL PENELITIAN}

\section{Gambaran Promosi}

Berdasarkan rekapitulasi skor dimensi yang memperoleh rata-rata skor tertinggi adalah periklanan (advertising) dengan persentase sebesar 38\% sedangkan dimensi yang memperoleh rata-rata skor terendah adalah promosi penjualan (sales promotion) dengan persentase sebesar $28 \%$. Hasil nilai kontinum promosi termasuk dalam kategori tinggi artinya yaitu melalui hasil pengukuran diketahui bahwa dalam variabel promosi yang diteliti dimensi periklanan (advertising), promosi penjualan (sales promotion) dan online and social media marketing berjalan dengan baik dalam penelitian ini.

\section{Gambaran Inovasi Produk}

Berdasarkan rekapitulasi skor dimensi yang memperoleh rata-rata skor tertinggi adalah keunggulan relatif dengan persentase sebesar 33\% sedangkan dimensi yang memperoleh rata-rata skor terendah adalah keseuaian atau keserasian dengan persentase sebesar 33\%. Hasil nilai kontinum inovasi produk termasuk dalam kategori tinggi artinya yaitu melalui hasil pengukuran diketahui bahwa dalam variabel inovasi produk yang diteliti dimensi keunggulan relative, kesesuaian atau keserasian, dan 
ketercobaan telah berjalan dengan baik dalam penelitian ini.

\section{Gambaran Keputusan Pembelian}

Berdasarkan hasil rekapitulasi skor dari dimensidimensi yang mempengaruhi terbentuknya keputusan pembelian. Dimensi yang memperoleh rata-rata skor tertinggi adalah pemilihan merek dengan persentase sebesar 38\% sedangkan dimensi yang memperoleh rata-rata skor terendah adalah metode pembayaran dengan persentase sebesar $25 \%$. Hasil nilai kontinum keputusan pembelian termasuk dalam kategori tinggi artinya melalui hasil pengukuran diketahui bahwa dalam variabel keputusan pembelian yang diteliti pilihan produk, pilihan merek dan metode pembayaran berjalan dengan baik dalam penelitian ini.

4. Pengaruh Promosi terhadap Keputusan Pembelian Honda Mobilio

Berdasarkan hasil pengujian secara parsial menunjukkan bahwa variabel promosi (X1) berpengaruh terhadap variabel keputusan pembelian (Y), artinya jika semakin tinggi tingkat promosi yang ditawarkan kepada calon konsumen, maka semakin tinggi pula calon konsumen yang memutuskan pembelian Honda Mobilio. Promosi (X1) berpengaruh positif dan signifikan terhadap keputusan pembelian (Y). Hal ini dapat dibuktikan dari hasil pengujian uji lisrel menunjukkan nilai Pengaruh total X1 terhadap $\mathrm{Y}=\mathrm{PY} 1+\mathrm{P} 21 \mathrm{P} 32=0.36+(0.82)(0.49)=0.76$, maka dapat disimpulkan bahwa Promosi yang ditawarkan Honda Mobilio memberikan nilai positif dalam mempengaruhi keputusan pembelian pada konsumen (pengguna Honda Mobilio). Hasil penelitian ini juga didukung oleh Susanto (2013) dalam penelitiannya yang menyatakan bahwa promosi berpengaruh positif dan signifikan terhadap keputusan pembelian. Semakin tinggi promosi yang ditawarkan maka semakin tinggi keputusan pembelian. Hasil penelitian Abshor, Hasiholan, dan Malik (2018) bahwa promosi berpengaruh signifikan terhadap keputusan pembelian.

\section{Pengaruh Inovasi Produk terhadap Keputusan} Pembelian

Berdasarkan hasil pengujian menunjukkan bahwa secara parsial variabel Inovasi produk (X2) mempunyai pengaruh terhadap variabel keputusan pembelian (Y), artinya jika semakin tinggi tingkat inovasi produk yang dilakukan, maka semakin tinggi pula calon konsumen yang memutuskan pembelian Honda Mobilio. Inovasi Produk (X2) berpengaruh positif dan signifikan terhadap keputusan pembelian (Y). Hal ini dapat dibuktikan dari hasil pengujian uji lisrel menunjukkan nilai Pengaruh total X2 terhadap $\mathrm{Y}=\mathrm{P} 32=(0.49)$, maka dapat disimpulkan bahwa Inovasi produk yang dilakukan Honda Mobilio memberikan nilai positif dalam mempengaruhi keputusan pembelian pada konsumen (pengguna Honda Mobilio). Hasil penelitian ini juga didukung oleh (Susanto, 2013) dalam penelitiannya yang menyatakan bahwa inovasi produk berpengaruh positif dan signifikan terhadap keputusan pembelian. Semakin tinggi inovasi yang dilakukan maka semakin tinggi keputusan pembelian. Menurut Haryono dan Fathoni (2018) bahwa inovasi produk berpengaruh positif terhadap keputusan pembelian.

6. Pengaruh Promosi dan Inovasi Produk terhadap Keputusan Pembelian

Hasil penelitian menunjukan bahwa berdasarkan uji hipotesis, hasil uji $\mathrm{t}$ variabel Promosi (X1) memiliki pengaruh signifikan secara parsial terhadap variabel Keputusan Pembelian (Y), dan Inovasi Produk (X2) memiliki pengaruh signifikan secara parsial terhadap variabel Keputusan Pembelian (Y) dengan nilai $\mathrm{t}$ hitung $>\mathrm{t}$ tabel sebesar adalah $1,00<$ 10,00 dan dengan nilai signifikan $0,000<0,05$. Hasil uji koefisien determinasi $\left(\mathrm{r}^{2}\right)$ yang bertujuan untuk mengetahui seberapa besar pengaruh inovasi produk terhadap keunggulan bersaing memiliki persentase sebesar $65 \%$. Penelitian inipun didukung oleh Jurnal (Amelia, 2016) hasil penelitian menunjukkan bahwa variabel promosi dalam penelitian ini berpengaruh signifikan pada periklanan (advertising), online and social media marketing dan promosi penjualan (sales promotion). Variabel inovasi produk dalam penelitian ini berpengaruh signifikan pada keunggulan relative, kesesuaian atau keserasian, dan ketercobaan. Dan variabel keputusan pembelian dalam penelitian ini berpengaruh signifikan pada pemilihan produk, pemilihan merek, dan metode pembayaran. Penelitian ini membuktikan dengan hasil nilai kontinum promosi dan inovasi produk sesuai data penelitian adalah termasuk dalam kategori tinggi artinya bahwa pengguna Honda Mobilio sudah baik dalam promosi dan inovasi produk pada Honda, Penelitian ini setuju dengan adanya promosi dan inovasi akan meningkatkan keputusan pembelian.

\section{PENUTUP}

\section{Simpulan}

Berdasarkan hasil penelitian yang telah dilakukan, maka kesimpulan yang dapat diambil dari penelitan ini adalah sebagai berikut :

1. Gambaran variabel promosi diukur melalui dimensi periklanan (advertising), online and social media marketing, dan promosi penjualan. Rata-rata skor tertinggi terdapat pada dimensi periklanan (advertising), dan rata-rata skor terendah terdapat pada dimensi promosi penjualan (sales promotion). Jadi dalam penelitian ini promosi berpengaruh positif dan signifikan terhadap keputusan pembelian Honda Mobilio. Artinya semakin tinggi promosi yang ditawarkan berakibat pada semakin tinggi keputusan pembelian Honda Mobilio.

2. Gambaran variabel inovasi produk diukur melalui dimensi keunggulan relatif, kesesuaian atau keserasian, dan ketercobaan. Rata-rata skor tertinggi terdapat pada dimensi keunggulan relatif, dan ratarata skor terendah terdapat pada dimensi kesesuaian atau keserasian. Jadi dalam penelitian ini inovasi produk berpengaruh positif dan signifikan terhadap 
keputusan pembelian Honda Mobilio. Artinya semakin tinggi inovasi produk yang dilakukan berakibat pada semakin tinggi keputusan pembelian Honda Mobilio.

3. Gambaran variabel keputusan pembelian diukur melalui dimensi pemilihan produk, pemilihan merek, dan metode pembayaran. Rata-rata skor tertinggi terdapat pada dimensi pemilihan merek, dan rata-rata skor terendah terdapat pada dimensi metode pembayaran.

4. Terdapat pengaruh positif dan signifikan promosi terhadap keputusan pembelian. Pengaruh langsung ini menunjukan bahwa Honda Mobilio mampu menciptakan promosi juga akan mampu memberikan keputusan pembelian yang baik.

5. Terdapat pengaruh positif dan signifikan inovasi produk terhadap keputusan pembelian. Pengaruh langsung ini menciptakan inovasi produk yang senantiasa meningkatkan keputusan pembelian pada Honda Mobilio.

6. Terdapat pengaruh positif dan signifikan promosi dan inovasi produk terhadap keputusan pembelian. Pengaruh ini menunjukan bahwa Honda Mobilio mampu menawarkan promosi yang menarik dan menciptakan inovasi produk yang senantiasa meningkatkan keputusan pembelian pada Honda Mobilio.

\section{Saran}

Adapun beberapa saran yang direkomendasikan pada penelitian ini yaitu:

\section{Saran kepada Perusahaan}

Berdasarkan hasil penelitian maka saran untuk perusahaan adalah :

a. Hasil penelitian menunjukkan bahwa indikator dari variabel promosi yang mempunyai pengaruh paling lemah terhadap keputusan pembelian adalah promosi penjualan, maka perusahaan perlu meningkatkan promosi penjualan produk yang beragam dan sesuai dengan kebutuhan masyarakat.

b. Hasil penelitian menunjukkan bahwa indikator dari variabel inovasi produk yang mempunyai pengaruh paling lemah terhadap keputusan pembelian adalah kesesuaian atau keserasian, maka perusahaan harus lebih menciptakan inovasi produk yang sesuai dengan nilai, kualitas produk, dan mengembangkan inovasi produk yang serasi.

c. Perusahaan harus memperhatikan promosi dan inovasi produk karena mempengaruhi keputusan pembelian terhadap Honda Mobilio.

\section{Saran kepada Peneliti Selanjutnya}

Peneliti selanjutnya diharapkan dapat melakukan penelitian lanjutan untuk mencari tahu pengaruh promosi dan inovasi produk terhadap variabel dependen lainnya, dan mampu melakukan penelitian dengan lebih sempurna serta mengurangi atau bahkan menghilangkan banyak keterbatasan yang ada dalam penelitian ini untuk penelitian selanjutnya sehingga penelitiannya dapat memberikan dedikasi yang jauh lebih baik.

\section{DAFTAR PUSTAKA}

Abshor, M. U., Hasiholan, L. B., \& Malik, D. (2018). PENGARUH HARGA, PROMOSI DAN KUALITAS PRODUK TERHADAP KEPUTUSAN PEMBELIAN PRODUK TORABIKA DUO (Studi Kasus Di Area Kabupaten Demak). Journal of Management, 4(4)

Erdiana, Nila. 2015. Analisis Pengaruh Kualitas Produk, Kesadaran Merek, dan Harga Terhadap Keputusan Pembelian Mobil Honda Mobilio di Kota Semarang. Skripsi. Fakultas Ekonomika dan Bisnis. Universitas Diponegoro Semarang.

Sekaran, Uma dan Bougie, R. 2017. Metode Penelitian untuk Bisnis Pendekatan. Pengembangan-Keahlian. Jakarta. Salemba Empat

Siswanto, A., Haryono, A. T., \& Fathoni, A. (2018). $\begin{array}{lcr}\text { PENGARUH } & \text { INOVASI } & \text { PRRODUK, } \\ \text { EKSPEKTASI } & \text { INOVASI } & \text { DAN NILAI } \\ \text { PELANGGAN } & \text { TERHADAP } & \text { KEPUTUSAN } \\ \text { PEMBELIAN } & \text { MOBIL DAIHATSU SIGRA DI } \\ \text { SEMARANG } & \text { DENGAN } & \text { KEPUASAN } \\ \text { PELANGGAN } & \text { SEBAGAI } & \text { VARIABEL }\end{array}$ PELANGGAN SEBAGAI VARIAB
INTERVENING. Journal of Management, 4(4).

Sugiyono. (2017). Metode Penelitian Kuantitatif, Kualitatif, dan R\&D. Bandung : Alfabeta,

Susanto, A. (2013). Pengaruh Promosi, Harga dan Inovasi Produk Terhadap Keputusan Pembelian pada Batik Tulis Karangmlati Demak. Tesis Universitas Negeri Semarang. (https://lib.unnes.ac.id/18429/)

www.motoris.id 